\title{
Atmospheric Radiation Measurement Program Climate Research Facility Operations Quarterly Report
}

October 1 - December 31, 2008

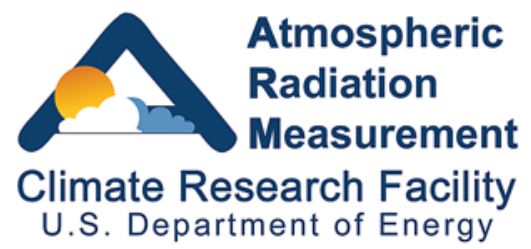

Work supported by the U.S. Department of Energy, Office of Science, Office of Biological and Environmental Research 


\section{Contents}

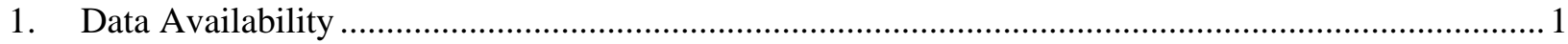

2. Site Visit Requests, Archive Accounts, and Research Computer Accounts .....................................2

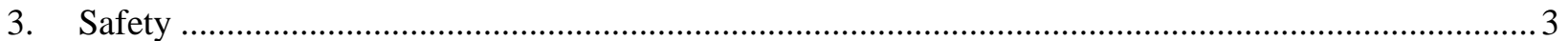

\section{Tables}

1. Operational statistics for the fixed ACRF sites for the period October 1 - December 31, 2008.......... 1

2. Summary of ACRF user site visits, archive accounts, and research computer accounts for the period January 1, 2008 - December 31, 2008. ......................................................................... 3

3. Consecutive days of injury-free operation for October 1 - December 31, 2008............................. 4 


\section{Data Availability}

Description. Individual raw data streams from instrumentation at the Atmospheric Radiation Measurement (ARM) Program Climate Research Facility (ACRF) fixed and mobile sites are collected and sent to the Data Management Facility (DMF) at Pacific Northwest National Laboratory (PNNL) for processing in near real-time. Raw and processed data are then sent daily to the ACRF Archive, where they are made available to users. For each instrument, we calculate the ratio of the actual number of data records received daily at the Archive to the expected number of data records. The results are tabulated by (1) individual data stream, site, and month for the current year and (2) site and fiscal year (FY) dating back to 1998.

The U.S. Department of Energy (DOE) requires national user facilities to report time-based operating data. The requirements concern the actual hours of operation (ACTUAL); the estimated maximum operation or uptime goal (OPSMAX), which accounts for planned downtime; and the VARIANCE [1 (ACTUAL/OPSMAX)], which accounts for unplanned downtime. The OPSMAX time for the first quarter of FY 2009 for the Southern Great Plains (SGP) site is 2,097.60 hours $(0.95 \times 2,208$ hours this quarter). The OPSMAX for the North Slope Alaska (NSA) locale is $1,987.20$ hours $(0.90 \times 2,208)$, and for the Tropical Western Pacific (TWP) locale is $1,876.80$ hours $(0.85 \times 2,208)$. The OPSMAX time for the ARM Mobile Facility (AMF) is not reported this quarter because the data have not yet been released from China to the DMF for processing. The differences in OPSMAX performance reflect the complexity of local logistics and the frequency of extreme weather events. It is impractical to measure OPSMAX for each instrument or data stream. Data availability reported here refers to the average of the individual, continuous data streams that have been received by the Archive. Data not at the Archive are caused by downtime (scheduled or unplanned) of the individual instruments. Therefore, data availability is directly related to individual instrument uptime. Thus, the average percentage of data in the Archive represents the average percentage of the time (24 hours per day, 92 days for this quarter) the instruments were operating this quarter.

Summary. Table 1 shows the accumulated maximum operation time (planned uptime), actual hours of operation, and variance (unplanned downtime) for the period October 1 - December 31, 2008, for the fixed sites. The AMF has been deployed to China, but the data have not yet been released. The first quarter comprises a total of 2,208 hours. The average exceeded our goal this quarter.

Table 1. Operational statistics for the fixed ACRF sites for the period October 1 - December 31, 2008.

\begin{tabular}{|r|r|r|r|r|r|}
\hline \multirow{2}{*}{ Site } & \multicolumn{3}{|c|}{ Hours of Operation } & \multicolumn{2}{c|}{ Data Availability } \\
\cline { 2 - 6 } & Opsmax & Actual & Variance & Goal & Actual \\
\hline NSA & $1,987.20$ & $2,097.60$ & -0.0556 & 0.90 & 0.95 \\
\hline SGP & $2,097.60$ & $2,075.52$ & +0.0105 & 0.95 & 0.94 \\
\hline TWP & $1,876.80$ & $2,141.76$ & -0.1412 & 0.85 & 0.97 \\
\hline Site Average & $1,987.20$ & $2,097.60$ & -0.0593 & 0.90 & 0.95 \\
\hline
\end{tabular}




\section{Site Visit Requests, Archive Accounts, and Research Computer Accounts}

Description. The Site Access Request System is a web-based database used to track visitors to the fixed and mobile sites, all of which have facilities that can be visited. The NSA locale has the Barrow and Atqasuk sites. The SGP site has a central facility, 23 extended facilities, 4 boundary facilities, and 3 intermediate facilities. The TWP locale has the Manus, Nauru, and Darwin sites. HFE represents the AMF statistics for the Shouxian, China, deployment in 2008. FKB represents the AMF statistics for the Haselbach, Germany, past deployment in 2007. NIM represents the AMF statistics for the Niamey, Niger, Africa, past deployment in 2006. PYE represents just the AMF statistics for the Point Reyes, California, past deployment in 2005. In addition, users who do not want to wait for data to be provided through the ACRF Archive can request a research account on the local site data system. The seven computers for the research accounts are located at the Barrow and Atqasuk sites; the SGP central facility; the TWP Manus, Nauru, and Darwin sites; and the DMF at PNNL. The ACRF also serves as a data repository for a long-term Arctic atmospheric observatory in Eureka, Canada, (8005' N, $86^{\circ} 43^{\prime}$ W) as part of the multiagency Study of Environmental Arctic Change (SEARCH) Program. NOAA began providing instruments for the site in 2005, and currently cloud radar data are available. The intent of the site is to monitor the important components of the Arctic atmosphere, including clouds, aerosols, atmospheric radiation, and local-scale atmospheric dynamics. Because of the similarity of ACRF NSA data streams and the important synergy that can be formed between a network of Arctic atmospheric observations, much of the SEARCH observatory data are archived in the ACRF Archive. Instruments will be added to the site over time. The designation for the archived Eureka data is YEU and is now included in the ACRF user metrics. This quarterly report provides the cumulative numbers of visitors and user accounts by site for the period January 1, 2008 - December 31, 2008.

DOE requires national user facilities to report facility use by total visitor days—-broken down by institution type, gender, race, citizenship, visitor role, visit purpose, and facility—for actual visitors and for active user research computer accounts. This information is maintained but not presented in this report.

Research computer accounts are counted in the same manner as for the ACRF Archive accounts: An individual is counted as only one unique user per site, even though he or she opens and closes an account several times to obtain different data at one or more sites. However, site visitors are counted each time they visit, because most visitors participate in multiple, unrelated experiments or events.

Also, users that visit sites can connect their computer or instrument to an ACRF network, which requires an on-site device account. Remote (off-site) users can also have remote access to any ACRF instrument or computer system at any ACRF site, which requires an off-site device account. These accounts are also tracked.

All user accounts are established for a period of up to one year and must be renewed annually. To report users, we counted the number of active users for the previous 12 months during the last month of the quarterly reporting period.

Summary. Table 2 shows the summary of cumulative users for the period January 1, 2008 December 31, 2008. For the first quarter of FY 2009, the overall number of users is down (about 20\%) 
from last quarter. Most of this decrease results from a reduction in the ACRF infrastructure users (e.g., site visits, research accounts, on-site device accounts, etc.) associated with the AMF China deployment. While users had easy access to the previous AMF deployment in Germany-resulting in an all-time high in user statistics - physical and remote access to on-site accounts are extremely limited for the AMF deployment in China. Furthermore, AMF data have not yet been released from China to the DMF for processing, which affects Archive user statistics. However, Archive users are down less than $10 \%$ from last quarter. Another reason for the apparent reduction in Archive users is that data from the Indirect and Semi-Direct Aerosol Campaign (ISDAC), a major field campaign conducted on the North Slope of Alaska, are not yet available to users.

The AMF was deployed in China with an anticipated operational start-up date of April 1, 2008. But, logistics and data communications issues resulted in delaying the official start-up date to May 19, 2008. The last operational day was December 29, 2008. Although the AMF collected data throughout its deployment, data communications issues were never fully resolved, and the stored observations made by the AMF still have not yet been provided to the DMF for processing. We are hopeful to have all raw data collected by the AMF released for processing in the next quarter. However, there are contributions to user statistics by the AMF deployment in China this quarter that are not related specifically to data, and they have been included in this report. This quarter, 24\% of the Archive users are ARM sciencefunded principal investigators and 51\% of all other facility users are either ARM science-funded principal investigators or ACRF infrastructure personnel.

Table 2. Summary of ACRF user site visits, archive accounts, and research computer accounts for the period January 1, 2008 - December 31, 2008.

\begin{tabular}{|c|c|c|c|c|c|c|c|}
\hline Site & Visitors & $\begin{array}{r}\text { Visitor } \\
\text { Days }\end{array}$ & $\begin{array}{r}\text { On-Site } \\
\text { Device } \\
\text { Accounts }\end{array}$ & $\begin{array}{r}\text { Off-Site } \\
\text { Device } \\
\text { Accounts }\end{array}$ & $\begin{array}{l}\text { Research } \\
\text { Accounts }\end{array}$ & $\begin{array}{r}\text { Archive } \\
\text { Accounts }\end{array}$ & $\begin{array}{r}\text { Total } \\
\text { Users* }\end{array}$ \\
\hline NSA & 109 & 1,546 & 6 & 39 & 20 & 178 & 352 \\
\hline SGP & 119 & 701 & 9 & 59 & 20 & 355 & 562 \\
\hline TWP & 29 & 183 & 6 & 42 & 23 & 211 & 311 \\
\hline \begin{tabular}{|l|} 
HFE \\
\end{tabular} & 46 & 1,568 & 3 & 24 & 9 & 0 & 82 \\
\hline FKB & & & & & & 44 & 44 \\
\hline PYE & & & & & & 31 & 31 \\
\hline NIM & & & & & & 60 & 60 \\
\hline$\overline{D M F}$ & & & & & 58 & & 58 \\
\hline YEU & & & & & & 5 & 5 \\
\hline Total & 303 & 3,998 & 24 & 164 & 130 & 884 & 1,505 \\
\hline
\end{tabular}

*Excludes visitor days.

\section{Safety}

For reporting purposes, the three ACRF sites and the AMF operate 24 hours per day, 7 days per week, and 52 weeks per year. Time is reported in days instead of hours. If any lost work time is incurred by any employee, it is counted as a work day loss. Table 3 reports the consecutive days since the last 
recordable or reportable injury or incident causing damage to property, equipment, or vehicle for the period October 1 - December 31, 2008. There were no incidents this reporting period.

Table 3. Consecutive days of injury-free operation for October 1 - December 31, 2008.*

\begin{tabular}{|r|r|r|c|c|}
\hline ES\&H Category & NSA & SGP & TWP & AMF \\
\hline Days Worked without a Lost-Time Incident & 92 & 92 & 92 & 92 \\
\hline Days Worked without a Recordable Accident & 92 & 92 & 92 & 92 \\
\hline Days Worked without a Property-Damage Incident & 92 & 92 & 92 & 92 \\
\hline Days Worked without a Reportable Loss to Vehicles & 92 & 92 & 92 & 92 \\
\hline
\end{tabular}

* "Injury-free” is defined as days without a recordable lost-time incident or property-damage incident. 